\title{
Decrease in gamma-glutamyl transpeptidase activity in early amniotic fluid in fetal trisomy 18 syndrome
}

\author{
HANNU JALANKO, PERTTI AULA
}

\begin{abstract}
A study was carried out in which activity of gammaglutamyl transpeptidase was measured in 259 samples of amniotic fluid obtained at various weeks of pregnancy. Two hundred and twenty-eight of the babies subsequently delivered had no chromosome abnormality and served as controls, while in 31 various chromosome abnormalities were detected. Mean activity of gamma-glutamyl transpeptidase in the control samples at 15 weeks was $602 \mathrm{U} / 1$. Activity in the samples obtained in cases of fetal chromosome abnormality was generally below this: it was below the 10 th percentile in $74 \%$ of the samples and below the 2.5 th percentile in $52 \%$ of the cases.

It is concluded that assay of gamma-glutamyl transpeptidase activity is a rapid preliminary test for prenatal diagnosis of chromosomal abnormalities.
\end{abstract}

\section{Introduction}

$\gamma$-Glutamyl transpeptidase is a membrane-bound enzyme present in many tissues and in several body fluids, especially bile and seminal plasma. ${ }^{1}$ We determined the activity of the enzyme in early amniotic fluid in pregnancies that subsequently had a normal outcome and in those in which the fetus was affected by chromosome disorders.

\section{Patients, methods, and results}

Altogether 259 samples of amniotic fluid, originally used for chromosomal analysis or assay of $\alpha$-fetoprotein concentrations, were available. The samples were collected by amniocentesis, and gestational

\footnotetext{
Department of Bacteriology and Immunology, University of Helsinki, Helsinki 29, Finland

HANNU JALANKO, MD, research assistant

Department of Obstetrics and Gynecology, University Centraj Hospital, Helsinki 29, Finland

PERTTI AULA, MD, senior lecturer (present address: Mount Sinai Medical Center, Division of Medical Genetics, New York, USA)
}

ages were estimated by ultrasonic scanning. Of the samples, 204 were obtained at 15 to 17 weeks of gestation, 35 at 18 to 20 weeks, and 20 during the third trimester of pregnancy. In 228 cases the infants subsequently delivered had no chromosome aberration, and these served as controls. Chromosomal abnormality was diagnosed in 31 cases, including trisomy 21 (19 cases; one case was $46 \mathrm{XX} ; \mathrm{i}(21 \mathrm{q})$ ) trisomy 18 (nine), trisomy 13 (one), XXY syndrome (one), and XO syndrome (one). Activity of $\gamma$-glutamyl transpeptidase was determined at $20^{\circ} \mathrm{C}$ according to the method of Szasz, ${ }^{2}$ using a $25 \mu \mathrm{l}$ or $50 \mu \mathrm{l}$ sample. Before the assay the samples, which had been stored at $-20^{\circ} \mathrm{C}$, were centrifuged at $2000 \mathrm{rpm}$ for 10 minutes. Statistical comparisons were made with Student's $t$ test.

Activity of $\gamma$-glutamyl transpeptidase in samples of normal amniotic fluid at 15 weeks of pregnancy varied from 252 to $1026 \mathrm{U} / 1$ (mean $602 \mathrm{U} / 1$ ). A progressive decrease in activity occurred with advancing pregnancy, the values averaging $219 \mathrm{U} / 1$ at 20 weeks and $19 \mathrm{U} / 1$ at 34-40 weeks of pregnancy. Seven of the nine samples from women whose fetus had the trisomy 18 syndrome showed enzyme activities below the 2.5 th percentile (fig (A)). The mean value in these samples

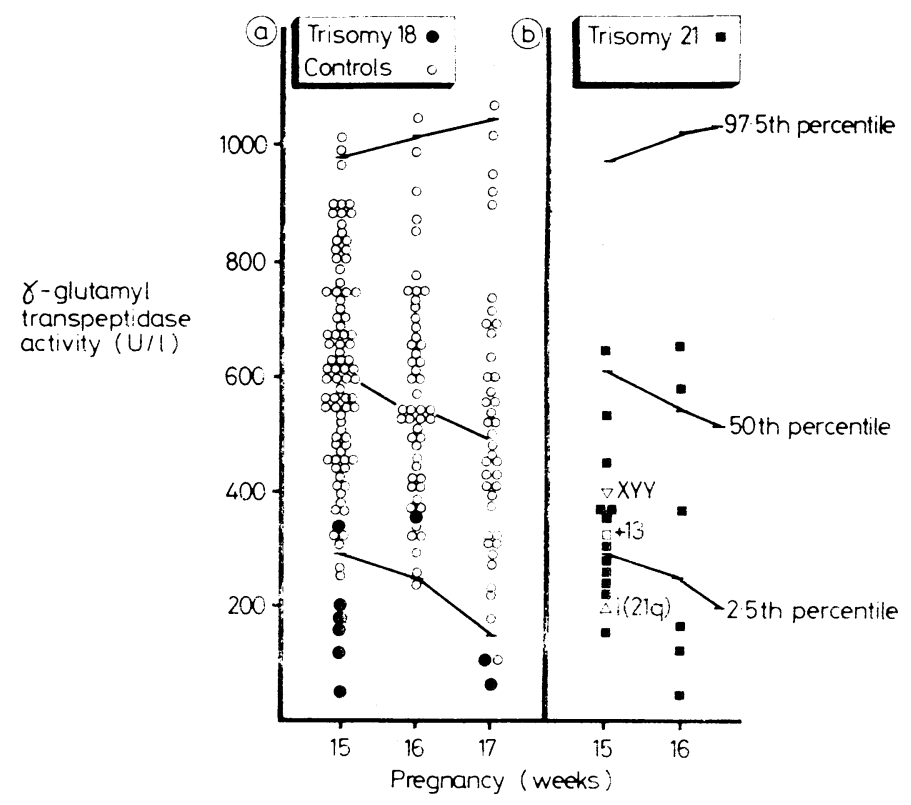

$\gamma$-Glutamyl transpeptidase activity in early amniotic fluid. 
at 15 to 16 weeks was one-third $(204 \mathrm{U} / \mathrm{l})$ of that observed in the controls $(598 \mathrm{U} / \mathrm{l})(\mathrm{p}<0.0005)$. In Down's syndrome (fig $(\mathrm{B}))$ the activity averaged $322 \mathrm{U} / 1 \quad(\mathrm{p}<0.0005)$ and fell below the 2.5 th percentile in nine of the 19 samples. The activity was within the normal range in one case of XO disorder (at 18 weeks; not shown).

\section{Discussion}

Activity of $\gamma$-glutamyl transpeptidase in early amniotic fluid was up to 100 times higher than that observed previously in maternal serum. ${ }^{1}$ Siegers et $a l^{3}$ reported that the mean activity in 17 samples of amniotic fluid obtained at 15-26 weeks' gestation was $426 \mathrm{U} / 1$. Our results agree with these findings. $\gamma$-Glutamyl transpeptidase probably enters the amniotic fluid from the surrounding fetal tissues, not from the maternal blood. This hypothesis is favoured by our recent findings that most of the enzyme activity is bound to complexes of high molecular weight, as analysed by gel filtration, and that the enzyme is demonstrable in several fetal tissues, such as the kidneys, small bowel, lungs, amniotic membranes, and placenta (unpublished observations)

To our knowledge this is the first time that a biochemical "disorder" has been observed in amniotic fluid in pregnancies in which the fetus is affected by a chromosome abnormality. The low $\gamma$-glutamyl transpeptidase activity is unlikely to be due to a specific gene disorder, since it occurred, to a variable extent, in several different syndromes. Autosomal abnormalities, especially trisomy 18 , adversely affect prenatal growth ${ }^{4}$ and the low enzyme activity may be caused by reduced leakage of the enzyme from hypoplastic fetal tissues. The low activity cannot, however, be explained solely by the growth deficiency, since in normal pregnancies the growth of the fetus is accompanied by a decrease, not increase, in amniotic fluid $\gamma$-glutamyl transpeptidase activity.

In our assay, in $74 \%$ of the samples from women whose fetuses had chromosomal aberrations activity of the enzyme was below the 10th percentile. If the activity was less than $300 \mathrm{U} / 1$ at $15-16$ weeks' gestation there was a $75 \%$ probability of chromosomal disorder, and if it was less than $200 \mathrm{U} / 1$ (10 samples) the probability was $100 \%$.

The importance of these findings remains to be established, but assay of $\gamma$-glutamyl transpeptidase activity would appear to be a useful additional test for prenatal diagnosis of chromosomal aberrations. The method is fast and simple and in common use in clinical laboratories for diagnosis of liver diseases.

We thank Miss Sirpa Kuisma for excellent technical help and the Finnish Cancer Foundation and the Orion Corporation Research Foundation for financial support.

Requests for reprints should be sent to Dr Hannu Jalanko, Department of Bacteriology and Immunology, University of Helsinki, Helsinki 29, Finland.

\section{References}

1 Rosalki SB. Gamma-glutamyl transpeptidase. In: Bodansky O, Latner AL, eds. Advances in clinical chemistry. Vol 17. New York: Academic Press, 1975:53-107.

2 Szasz G. A kinetic photometric method for serum gamma-glutamyl transpeptidase. Clin Chem $1969 ; \mathbf{1 5}: 124-36$.

Siegers C-P, Younes M, Siegers F, and Klink F. Gamma-glutamyl transpeptidase activity and glutathione content in the human amniotic fluid. IRCS fournal of Medical Science 1981;9:793.

1 Yunis JJ. New chromosomal syndromes. New York: Academic Press, 1977.

\title{
Sterile microenvironment in prevention of wound infection
}

\author{
JOHN M SCOTT, JAMES MCLAUCHLAN, H G SMYLIE
}

\begin{abstract}
A prospective controlled trial was carried out to assess the effect of using a wound isolator on reducing postoperative infection. A total of 291 patients undergoing hip pinning for fractures of the neck of femur entered the trial and were allocated at random to have their wound contained in a wound isolator (study group) or dressed with a standard gamma-irradiated adhesive dressing (control group). The bacteriological flora of the patient was monitored before, during, and after operation and that of the ward before and after. No significant difference was found in the flora of the wards in which the patients were nursed. On several occasions the source of the infective organism was traced to the ward but never to the theatre.
\end{abstract}

The isolator prevented direct contamination and airborne cross-infection of the wound and appreciably reduced the rate of infection.

Aberdeen Royal Infirmary, Aberdeen AB9 2ZB

JOHN M SCOTT, MB, FRCSED, lecturer in orthopaedics

University of Aberdeen, Aberdeen AB9 1FX

JAMES MCLAUCHLAN, CHM, FRCSED, reader in orthopaedic surgery H G SMYLIE, MD, FRCPATH, senior lecturer in bacteriology

\section{Introduction}

Wound infection is one of the most serious problems in surgery and argument continues on the relative importance of the various sources of infection in the total environment of the patient undergoing surgery. With the advent of total hip replacement the unacceptably high incidence of postoperative wound infection led workers to look more closely at the environment of the patient and particularly at the theatre environment and routine. Professor Sir John Charnley felt that infection after total hip replacement was caused by organisms from the theatre atmosphere settling into the wound. After introducing a clean air theatre with 300 air changes per hour and a body exhaust system he reduced his infection rate after low-triction arthroplasty from $9.5^{\circ} \%$ to $0.4^{\prime}, .^{1}$ Unfortunately insufficient monitoring of the bacteriological flora of the patient's total environment in such studies leaves doubt as to the exact source of any infection. We therefore conducted a study of the surgical isolator ${ }^{2}$ in total hip replacement, monitoring the bacteriological flora of the patient before, during, and after every operation and of the operative environment during every procedure. We found that the opportunities for superficial or deep infection were greater in the ward than in the operating theatre. ${ }^{3}$ As a result of these findings a sterile microenvironment for postoperative wound care was developed. ${ }^{4}$ This isolator (figure) contains wounds in a sterile environment until they have healed and prevents direct contact and airborne cross-infection. We describe the efficiency of this sterile microenvironment in reducing postoperative wound infection after hip pinning. 